\title{
Sociološka dimenzija britanskih kulturalnih studija
}

\section{Andriana Benčić}

\author{
Filozofski fakultet u Zagrebu, Poslijediplomski doktorski studij sociologije, \\ Hrvatska \\ e-mail: andriana.bencic@gmail.com
}

\begin{abstract}
SAŽETAK Rad nastoji pružiti opširan kritički pregled sociološke dimenzije i socioloških značajki britanskih kulturalnih studija. U tom kontekstu, nudi nove teorijske poticaje za revalorizaciju i ponovno promišljanje uloge britanskih kulturalnih studija na području sociološke znanosti. Britanski kulturalni studiji su u svojoj multidisciplinarnosti uvijek bili izuzetno povezani sa sociologijom te su u velikom dijelu svoga habitusa, koji je načelno interdisciplinaran, neka vrsta eklektične sociologije. Bogatstvom i kvalitetom svojih pristupa ti studiji obogaćuju i osvjetljavaju sociološki pristup. Iako britanski kulturalni studiji zauzimaju svoje mjesto u sociologiji u vidu neomarksističke teorije kulture, još uvijek nije na sustavan i obuhvatan način iznesena niti dovoljno problematizirana sociološka dimenzija britanskih kulturalnih studija. Sociološka dimenzija britanskih kulturalnih studija u radu je najopsežnije prikazana u osvrtu na britansku birminghamsku školu kulturalnih studija u cjelini, s posebnom usredotočenošću na ideje Antonija Gramscija koje su najsnažniji teorijski oslonac britanskih kulturalnih studija. U sklopu zajedničkoga sociopolitološkog teorijskog okvira sociologije kulture i britanskih kulturalnih studija problematizira se uklopljenost kulturno-komunikacijskoga sklopa u mrežu ekonomske i političke moći.
\end{abstract}

Ključne riječi: britanski kulturalni studiji, sociologija, kultura, sociologija kulture, moć, sociopolitološko razmatranje kulture.

\section{Uvod}

Kulturalni studiji ${ }^{1}$ su interdisciplinarno, multidiskurzivno, holističko i sinkretično područje, te u svom habitusu bilježe niz različitih povijesti, formacija i oblika rada. U svome razvoju i interdisciplinarnosti bili su gotovo uvijek u bliskom dosluhu

$\mathbf{1}$ Jezični stručnjaci više su puta upozoravali na terminološki problem prilikom korištenja pridjeva "kulturalni" i "kulturni". U hrvatskom je jeziku pravilnije koristiti pridjev "kulturni" (koji se odnosi na kulturu), čime engleska inačica "kulturalni" (cultural) zapravo postaje suvišna. S druge strane, ne možemo zanemariti prvenstvo i uvriježenost, pa time i pretežitost upotrebe sintagme kulturalni studiji u Hrvatskoj. Jedini zasebni studij organiziran na diplomskoj razini u Rijeci u svome nazivlju koristi sintagmu kulturalni studiji. S obzirom da u radu konzultiramo literaturu koja isključivo rabi pridjev "kulturalni", zbog dosljednosti i jezične koherentnosti ovoga rada studije o kulturi odabrali smo naslovljavati kulturalnima. 
sa sociologijom, a do sada nije, osobito u sociologiji, dovoljno problematizirana sociološka dimenzija kulturalnih studija. U ovom ćemo se radu baviti izvornom britanskom školom kulturalnih studija koja se, kao jedna od neomarksističkih teorija kulture, smatra konstitutivnim dijelom sociološke znanosti (Haralambos i Holborn, 2002.:895-898; Johnson, u: Duda, 2006.; Kalanj, 2000.:42-46). Iako su u multidiskurzivnosti svoga područja britanski kulturalni studiji često bili skloni isticati upravo sociološki diskurs kao prevladavajući, sve do danas nije na pregledan način prikazana sociološka dimenzija britanskih kulturalnih studija. Treba naglasiti da sociologija ostaje bitno osiromašena u nedostatku interdisciplinarnoga dijaloga s britanskim kulturalnim studijima te da je nužno uvesti bogatiji i širi kritički dijalog između dvaju područja. Takav bi nas pothvat približio sustavnijem i utemeljenijem razumijevanju samoga sociološkog pojma kulture čija konceptualna višeznačnost uvijek zahtijeva nova hermeneutička razjašnjenja.

Na početku rada iznijet ćemo sažet povijesni prikaz koncepta kulture u sociologiji od vremena prvih socioloških paradigmi do pojave sociologije kulture, kako bismo kasnije mogli kontekstualizirati britanske kulturalne studije i njihove uvide o kulturi na području sociologije. U radu ćemo nadalje nastojati prikazati doprinos britanskih kulturalnih studija sociologiji, odnosno ono teorijsko i metodološko pojmovlje britanskih kulturalnih studija koje je po svojoj znanstvenoj naravi ${ }^{2}$ sociologijski ukotvljeno, pritom neprestano upozoravajući na nedovoljnu uvrštenost i obrađenost pojmovlja i rada britanskih kulturalnih studija na području sociologije. Drugim riječima, britanski kulturalni studiji bili su zaokupljeni brojnim sociološkim kategorijama te su se bavili suptilnim sociološkim analizama. Stoga je od velike znanstvene važnosti za sociologiju, a osobito sociologiju kulture, označiti koje je to pojmovlje britanskih kulturalnih studija i upozoriti na nužnost njegova sociološkoga razumijevanja. S obzirom da je današnja kultura u tolikoj mjeri eksplicitna i izražena u vidu moći tehnoznanosti, medija, novca, stranačkih i državnih birokracija, najopsežniji dio naše rasprave o britanskim kulturalnim studijima i njihovoj sociološkoj dimenziji bit će iznesen u teorijskom okviru sociopolitološke problematizacije kulture. Posebnu pažnju posvetit ćemo talijanskom marksističkom filozofu Antoniju Gramsciju koji je uvelike utjecao na britanske kulturalne studije. Gramscijev rad nudi vrijedna polazišta za sociopolitološku analizu pojma moći. Svijest o politizaciji kulture i jest

2 Treba napomenuti da je opća, interdisciplinarna, holistička i multidiskurzivna narav kulturalnih studija uvijek u bijegu i odmaku od znanstvene objektivnosti te da su oni s time u skladu tek uvjetno nazvani disciplinom. Tonny Bennet govori da kulturalne studije određuju dva pravila od kojih je jedno pravilo teorijske i metodološke neodlučnosti (Bennett, 2005.), a Hartley to pravilo jezgrovito opisuje prikazom kulturalnih studija u kojemu se oni, u širokoj nesklonosti da se identificiraju "prepoznaju po preosjetljivosti na ortodoksiju onih koji u njima sudjeluju, nadalje prepoznaju se u izostanku jedne jedinstvene teorije, tekstualnoga kanona, disciplinarne istine, dogovorene metodologije i zajedničkoga nastavnog programa, ispitnoga gradiva ili profesionalne zajednice" (Hartley, 1991.:7). Slikovit opis prirode kulturalnih studija ponudio je Dunn: "Kulturalni studiji su u vrtnji, i miran i zanjihan mobil u kojemu se stalno premještaju svi subjekti što u njemu sudjeluju (...) projekt kojemu je suđeno da nikad ne stekne definitivno stajalište o sebi jer se njegova realizacija zauvijek odgađa" (Dunn, 1986.:71, u: Bennett, 2005.:45). 
osnovno obilježje britanskih kulturalnih studija te je njihova sociološka dimenzija najvidljivija u razmatranjima kulture kao reproduktivne dimenzije stratifikacije, diferencijacije, moći i dominacije. Britanski kulturalni studiji jedna su od najranijih teorijskih varijanti koji analitički povezuju kulturu i moć te postavljaju pitanje kako se kultura oblikuje i koristi kao resurs političke moći.

U završnom dijelu rada upozorit ćemo na potrebu širega sagledavanja sociološke dimenzije britanskih kulturalnih studija u hrvatskoj akademskoj sociologiji koja se općenito u svojim izvedbenim nastavnim programima i kurikulumima nedovoljno bavi britanskim kulturalnim studijima.

\section{Sociologija i kultura}

Razmišljanja, učenja i pisanja o kulturi i raznorodnim pojavama vezanim uz taj koncept, dovest će nas do gotovo izlizane tvrdnje Raymonda Williamsa - "riječ kultura jedna je od dvije ili tri najzamršenije riječi u engleskom jeziku” (Williams, 1976.). Nećemo pogriješiti ako kulturu i danas proglasimo kanonskim meta pojmom znanstvenoga diskursa. U smislu svoje definicijske višeznačnosti, nerijetko označavane sintagmama pojmovnoga kaosa ili pojmovne džungle, kultura uistinu jest složen koncept. No, zamršenost i multidimenzionalnost koncepta kulture ne trebaju uplašiti i obeshrabriti, već trebaju usmjeriti na pokušaj razumijevanja i analize njezinih strukturalnih elemenata. Potrebno je usustavljanje i preispitivanje mnogih humanističkih i društvenih disciplina koje, svaka iz habitusa svoje discipline, govore o raznim aspektima kulture.

Uz nekolicinu drugih znanosti, sociologija ima određeno prvenstvo u određivanjima značenja kulture. Razlog tomu je neizbježna činjenica formiranja sociologije kao znanosti u vremenu "velike preobrazbe" moderniteta na Zapadu (Polany, 1957.), gdje je kultura bila ključan faktor tih preobrazbi. Jedna od najobuhvatnijih definicija kulture (u smislu življenja i svakodnevice, odnosno njena neposrednoga značenja za čovjeka) upravo je socioantropološka definicija; kultura je ukupnost načina života društva (Clarke et al., 1976., u: Hall i Jefferson, 1976.; Jencks, 1993.; Eagleton, 2002.; Linton, 1945.; Williams, 1965.). U tom značenju kultura zapravo obuhvaća cjelinu predmeta sociologije. Isprepletenost pojmova kulture i društva, kulture i civilizacije, kulture i identiteta, kulture i politike ili kulture i ekonomije, pomalo je opasne naravi u znanstveno-klasifikacijskom smislu jer dovodi do toga da je sociologiju kulture teško izdvojiti kao različitu od drugih područja sociologije. Usprkos povremenoj marginalizaciji kvalitativnih kultur(al)nih analiza u sinkronijskom razvoju sociologije, kulturu treba označiti kao sveprisutni sociološki pojam. Koncept kulture na razne je načine i u različitim ekspresivnim oblicima u sociologiji prisutan od samih početaka njena formiranja. Kultura je štoviše, u ranoj sociologiji, otvarala mjesto načinima promišljanja društvenih razlika s dubinom i bogatstvom koji nisu bili ostvarivi u grubim pozitivističkim modelima istraživanja koji su činili mainstream sociologije kasnije, u vremenu njene sveučilišne institucionalizacije. 
Treba napomenuti kako je rana sociologija, iako je sam pojam kulture izrijekom vrlo rijetko rabila, sadržavala vrlo sofisticirane kulturalne uvide i analize. U ranom dvadesetom stoljeću kultura nije bila autonomna te je u neizdiferenciranosti svoga koncepta često funkcionirala kao označiteljica društvenoga. Marx, koji je rijetko upotrebljavao pojam kulture, rekao je da je kultura praksa koja realizira ili objektivira život grupa u značenjske oblike i forme. "Način na koji individue iznose svoj život, to je ono što oni jesu. To se podudara s njihovom proizvodnjom; i onime što proizvode i načinom na koji to proizvode" (Marx, 1970.:42).

U funkcionalizmu, Parsonsova teorija kulture sastavni je dio njegovih teorija o društvu kao cjelini. U svom djelu Društveni sustav pridao je kulturi vrlo značajnu ulogu, odredivši ju kao "izražajne simbole ili vrijednosne obrasce" koji omogućuju da se različiti elementi društvenoga sustava povežu u cjelinu. Kultura je za Parsonsa funkcionalni preduvjet opstanka svakoga društva (Parsons, 1951., u: Haralambos i Holborn, 2002.:897).

Weber je implicirao razne kulturološke aspekte u svom najpoznatijem djelu Protestantska etika $i$ dub kapitalizma, tako što je razmatrao odnos između određenih oblika protestantizma i razvoja zapadnoga industrijskog kapitalizma. Dokazao je kako duh kapitalizma nije samo način da se stekne novac (kapitalističku praksu Weber ocrtava knjigama Benjamina Franklina), već način života, odnosno svojevrsna kultura življenja koja posjeduje svoju etiku, dužnost i obveze. U svojim je analizama nastojao otkriti u kojoj je mjeri religija utjecala na razvoj toga duha i došao je do tvrdnje da je asketski protestantizam, a osobito kalvinizam, svojim načinom života - svojom kulturom, bitno utjecao na nastanak i razvoj racionalnoga kapitalizma u zapadnoj Europi (Weber, 1968.).

Durkheim je također u svojim najpoznatijim djelima integrirao kulturalne forme. Tvrdio je da čovjek preko kolektivnih reprezentacija, totema i simbola, zapravo štuje društvo. Govorio je da je društveni život nemoguć bez zajedničkih vrijednosti i moralnih uvjerenja koje tvore kolektivnu svijest, a religija je ta koja jača kolektivnu svijest jer okupljanje na religioznim obredima, u visoko nabijenoj atmosferi kolektivne pobožnosti, zapravo utječe na jačanje integracije društva. Preko rituala se stvara svijest o jedinstvu grupe pa religija unapređuje društvenu solidarnost. Suština religije je društvo, a čovjek stvara religiju kao integrativnu funkciju da bi društvo opstalo u zajedničkim vrijednostima i normama. Misao da je religija "najtipičnija za društvenu integraciju pojedinca", Durkheim iznosi u Elementarnim oblicima religijskog života, gdje ujedno izlaže vjerojatno najutjecajniju interpretaciju religije s funkcionalističkoga stajališta (Durkheim, 1970.). U prilog kulturi govori i Durkheimov pojam anomije kao poremećaja ravnoteže u društvu i kulturi, koji vodi samoubojstvu. Jeffrey Alexander, istaknuti suvremeni sociološki teoretičar i zastupnik "strogog programa" kulturne sociologije, smjera kojega je sam razvio usporedno sa sociologijom kulture izazvavši tako mnoge polemike u akademskoj i javnoj sociologiji, uzima upravo Durkheima i njegov rad kao primjer klasične sociološke tradicije koji je ujedno izvrstan model suvremene sociologije u vidu davanja visoke teorijske autonomnosti kulturi. Alexander na tome tragu ističe da kulturalni studiji, koji sagledavaju kulturu kao autonomnu sferu, nisu ništa novo u sociologiji, već datiraju iz Durkheimove 
sociologije. Alexander osobito naglašava Durkheimovu kasniju studiju religije koja kulturalnim procesima daje autonomnost tako što iznosi sociološke činjenice i one značajke socijalnoga života koji su izvan društvenih aktera.

Nadalje, uključenost kulture u sociologiju možda je najvidljivija u pragmatičnosti čikaške sociološke škole ${ }^{3}$ i simboličkog interakcionizma. Sociokulturne analize čikaške škole o supkulturama, devijantnosti, etnicitetu, rasi, crnačkim četvrtima ("obojene urbane lokacije"), ubrajaju se među sociološki najistančanija razumijevanja kulturnih razlika (Haralambos i Holborn, 2002.:217-220). Neki od ranih autora kulturalnih studija koji su radili na proučavanju supkultura u Birminghamu, bili su pod utjecajem čikaške škole. Simbolički interakcionizam, razvijen na teorijskim uvidima C. H. Cooleya, W. I. Thomasa i G. H. Meada o interaktivnoj konstrukciji jastva i društvenoga identiteta, te koncentriran na proces interakcije ljudi u posebnim konceptima, što uključuje istraživanje konstrukcije značenja, slično afinitetima kulturalnih studija, govori o kompleksnosti socijalne konstrukcije identiteta i značenja, o svakodnevici i socijetalnim grupama te o njihovim semantičkim i kulturnim značajkama.

Treba posebno upozoriti da je početkom pa sve do sredine dvadesetoga stoljeća, u vremenu svoje sveučilišne institucionalizacije, sociologija marginalizirala kulturu u skladu s disciplinarnom teorijskom i metodološkom rigoroznošću te vrijednosnom neutralnošću koje je morala promicati kako bi se etablirala kao prepoznatljiva i od drugih grana odijeljena disciplina. Zatvaranje sociologije u akademske krugove kao i njena pozitivistička i empirijsko-deskriptivna usmjerenost rezultirali su određenim vidom sljepoće za vitalna društvena događanja i procese. S obzirom da je još dugo vremena nakon institucionalizacije nastavila djelovati kao hermetična i legitimirajuća disciplina, nedovoljno interpretativna i nedovoljno refleksivno-kritična, sociologija se još i danas suočava s nedostacima svoje znanstvenosti. Suočava se s vlastitim statusom i vrijednostima te prije svega s društvom koje je već nakon Drugoga svjetskog rata postalo nepovratno obilježeno velikim kulturnim promjenama i konfliktima po pitanju političke moći i društvenih identiteta vezanih za nove spolne, rodne i rasne odnose, a sve u globalnim uvjetima ekonomskoga rasta, konzumerizma, sofisticiranih tehnologija i medija (te njihovoga rapidnog povećavanja i širenja). Javila se velika potreba za teorijom (ili teorijama) koja će znati objasniti društveni konflikt, promjene i kulturnu različitost.

3 Čikaška se škola na društvenoj sceni javlja se ranije od kulturalnih studija, krajem 19. stoljeća, uz osobit utjecaj 1920-ih i 1930-ih godina. Škola je bila poznata po vještini i izvrsnosti svojih članova u povezivanju teorijske akademske djelatnosti i praktične djelatnosti na sveučilištu u Chicagu. Čikaška je škola u širem kontekstu utjecala i na razvoj kulturalnih studija, osobito na studiju o supkulturama birminghamca Phila Cohena Subcultural Conflict and Working-Classcommunity (1972.). U odnosu na kulturalne studije, koji se primarno pojavljuju u drugačijim vremenskim i prostornim uvjetima, čikaški urbani sociolozi bili su za razliku od teoretičara kulturalnih studija usko usredotočeni na ekološki pristup gradu Chicagu, koji je bio laboratorij i polazište svih njihovih istraživanja. 
Kako je sociologija s obzirom na habitus svoje discipline prva koja je pozvana da ponudi odgovore na suvremenu društvenu problematiku, ideali pozitivne, empirijske, neutralne i objektivne sociologije, odvojene od javne sfere, u takvim su uvjetima neizbježno morali biti dovedeni u pitanje ${ }^{4}$. Sociologija se tako u okvirima vlastitoga znanstvenog i praktičkog previranja našla na nimalo jednostavnom putu gdje je trebala (morala) otvoriti svoje znanstvene horizonte prema revizijama u svijetu novih informacija, novih znanja, obrazaca, normi i vrijednosti.

I naposljetku, sada kada su akademska znanja društvenih i humanističkih znanosti uzdrmana globalizacijom i globalnim razvojem koji odavno osporavaju zapadnjačke prosvjetiteljske ideje racionalnosti, kontinuiranoga progresa i objektiviteta, javlja se refleksivnije i interpretativnije postavljena grana sociologije koja prepoznaje društvenu važnost popularne, masovne kulture u odnosima konzumerizma, konstrukcije identiteta te kulturne i političke moći, i naziva se sociologijom kulture. Sociologija kulture područje je sociologije koje se pojavljuje u novije moderno doba kao odgovor na svakodnevne sociokulturne fenomene, s ciljem da na njih ukaže te da ih pokuša razumjeti, istražiti i objasniti. Suvremeni teoretičari kulture u potrazi za iznalaženjem novih teorija i pristupa koji će moći odgovoriti na brojne kultur(al)ne izazove (post)modernoga doba, zamjeraju sociologiji kulture njeno pretežito djelovanje i zadržavanje "u terminima modernističke sigurnosti, stabilnosti klasifikacija" (Silverstone, 1994., u: Wolff, 1999.). Navedeni određujući faktor sociologije kulture ujedno i glavna prepreka povezivanju suvremenih kulturalnih studija i sociologije kulture. Problem je u tome što sociologija kulture još uvijek pretežito djeluje kao analiza kulturne evolucije normi i institucija kao temeljnih elemenata društvenoga sustava, dok se suvremeno društvo rizika (izraz Ulricha Becka) očituje u metafori života na eruptivnom vulkanu raznolikih identiteta gdje je ontološka sigurnost pojedinca itekako dovedena u pitanje i gdje se na nekadašnju sigurnost institucija više nije moguće osloniti. Istina je kako je sociologija kulture i nakon kulturalnoga obrata nastavila razumijevati društvene kategorije i institucije kao koherentne i stabilne entitete, te je na taj način dijelom zaostala u sagledavanju diskurzivne prirode društvenih odnosa i institucija. No, riječ je o disciplini koja je još uvijek u razvoju, te se mijenja zajedno s promjenom značenja koncepta kulture u suvremenim globalnim okolnostima. S

${ }^{4}$ O pretjeranom objektivizmu i pozitivizmu socioloških metoda u hrvatskoj sociologiji govori u više navrata Inga Tomić-Koludrović. Ona u svome tekstu Pogled u budućnost: sociologija kao multiparadigmatska, refleksivna i javna znanost, objavljenom u Reviji za sociologiju krajem 2009. godine (Vol. 40 (39) No. 3-4), iznosi niz stavova koji upućuju upravo na potrebu za preispitivanjem sociologije kao znanosti. Konstatira da su sociologija kao disciplina i njezini istraživački rezultati nedovoljno vidljivi u tranzicijskom hrvatskom društvu, a uzroci takvom stanju pronalaze se u ulozi legitimacije društvenoga poretka, koja je sociologiji kao disciplini bila namijenjena tijekom socijalističkog razdoblja. U takvoj prošlosti discipline valja tražiti razloge nedovoljne teorijske i metodologijske spremnosti hrvatske sociologije da odgovori na kompleksne procese s kojima se hrvatsko društvo suočava u postsocijalističkom razdoblju. Tomić-Koludrović ističe da, kako bi ispunila svoju javnu ulogu, hrvatska bi sociologija trebala nastaviti aktualna nastojanja prema metodološkoj raznolikosti i usvajanju multiparadigmatskih teorijskih pristupa. Također bi, kao disciplina, trebala poraditi na svojoj samorefleksivnosti i nastojati postići što viši stupanj akademske izvrsnosti (Tomić-Koludrović, 2009.:139). 
druge strane, recentnu znanstvenu činjenicu o "krutosti" i stabilnosti entiteta u sociologiji kulture ne treba sagledavati isključivo kao nedostatak sociološke znanosti. Štoviše, Avery Gordon govori da sofisticirano razumijevanje reprezentacija i načina kako je društveni svijet diskurzivno oblikovan još uvijek zahtijeva vezu s društveno strukturiranim praksama koje su dugo dio sociologije (Gordon, u: Wolff, 1999.:7). Sociolozi mogu itekako doprinijeti projektu kulturalne analize upravo fokusom na strukturu socioloških kategorija, odnosno uvidom u strukture i povijesne transformacije klase, rase, roda, statusa, nacionalnosti, identiteta. Ne želeći ni na koji način osporiti kultur(al)ne pristupe u kojima se društvo i njeni entiteti sagledavaju kao povijesno i diskurzivno oblikovani, ipak treba upozoriti na sljedeće - ako te društvene entitete shvatimo isključivo kao povijesne artikulacije i diskurzivne konstrukte koji se uvijek mijenjaju, na što se uopće možemo osloniti? Kada ne bismo imali određenu "čvrstoću društvenoga svijeta", o čemu bi teorije kulture (i suvremeni kulturalni studiji) koje ne mogu biti samo diskurzivne i tekstualne, uopće mogle ovisiti? (Goodwin i Wolff, u: Long, 1997.:123-155). Zbog primarne zaokupljenosti ovoga rada doprinosima britanskih kulturalnih studija sociologiji nismo u prilici dublje zalaziti u brojna i kontroverzna pitanja suvremenih teorija o kulturi. Prije no što započnemo s analizom britanskih kulturalnih studija i njihove prevladavajuće sociološke dimenzije, ukratko ćemo naznačiti najvažnije smjernice suvremenih kulturalnih studija.

Unatoč tome što su upravo britanski kulturalni studiji kolijevka kulturalnih studija, to je područje, kako smo već naznačili, interdisciplinarno, multidiskurzivno i sinkretično, te u svom habitusu bilježi niz različitih povijesti, formacija i oblika rada. Kulturalni studiji razvili su se u mnogo različitih formi, bez jasnoga središta, te su korišteni na razne načine. Drugačije nacije razvile su drugačije oblike kulturalnih studija, kao što su razvile drugačije kulturnopolitičke pozicije i intelektualne smjernice u svom oslanjanju na kulturalne studije (During, 2005.). U najširem smislu, kulturalni studiji su studiji kulture koji "teže razumijevanju funkcioniranja kulture u suvremenom društvu, te se bave načinima na koje se konstruiraju i ustrojavaju individualni i grupni identiteti u svijetu raznolikih i izmiješanih zajednica, državne moći, medijske industrije i multinacionalnih kompanija" (Culler, 2001.:53). Danas ih, dakle, treba razumjeti kao globalizirane i u svjetskim razmjerima. Suvremeni kulturalni studiji zaokupljeni su svim kulturama kao poljima pomicanja granica i hibridizacije (Bhabha, 1994.). Pitanje kulture danas je neodvojivo od koncepta identiteta, pa se kulturalni studiji uvijek bave i kulturalnim identitetima kao kompleksnim hibridnim tvorbama koje treba proučiti (Barker, 2003.; Bhabha, 1994.; Eagleton, 2002.; Hall, 1997.). ${ }^{5}$ U srži kulturalnih studija udruženost je društvene i kulturne mobilnosti te kulturnoga miješanja i supostavljanja sa sve bržom globalizacijom (posebice razvojem elektron-

5 Iako su svi navedeni teoretičari kulture važni za razumijevanje i promišljanje suvremenoga koncepta kulture i njene neodvojivosti i obilježenosti globalizacijom, valja posebno istaknuti djelo Terryja Eagletona, učenika Raymonda Williamsa. Eagleton u svojoj knjizi Ideja kulture (The Idea of Culture) (2000.), uz ostala razmatranja o kulturi kojima se u knjizi bavi, sociološki vrlo suptilno sugerira promišljanje i promjenu koncepta kulture s obzirom na procese globalizacije koji na nju utječu. Kulturu zbog toga više ne možemo razumjeti u smislu točno lokaliziranoga mjesta, već je trebamo razmatrati kao izmještenu, kao niz hibridnih i kreoliziranih kulturalnih puteva u globalnom svijetu (Eagleton, 2002.). 
skih komunikacija), koju pak nije moguće promatrati izvan njenoga začetničkog okvira neoliberalnoga kapitalizma.

\section{Britanski kulturalni studiji i njihova sociološka dimenzija}

Uz svjesnost o povijesnom razvoju sociologije i sociološkoga koncepta kulture - s osobitim naglaskom na vrijeme sveučilišne institucionalizacije sociologije gdje je kultura bila marginalizirana zbog potrebe da se znanost disciplinarno omeđi kao vrijednosno neutralna, ne čudi da neke od najvećih poslijeratnih društvenih diskusija o kulturi ostaju izvan sociologije. Zbog toga je od velike važnosti za sociologiju upozoriti na nedovoljnu uvrštenost rada britanskih kulturalnih studija u njenu sferu. Britanski kulturalni studiji oduvijek su bili izuzetno povezani sa sociologijom, a do sada nije, osobito u sociologiji, dovoljno problematizirana niti na pregledan način iznesena njihova sociološka dimenzija. Britanski kulturalni studiji nude niz društvenih analiza i pristupa kojima obogaćuju i osvjetljavaju sociološki pristup te djeluju kao jedna vrsta eklektične sociologije u godinama kada sociologija sama nije bila u mogućnosti pružiti kvalitetan (kao i kvalitativan) alat za analizu tada sveprisutnih, a neistraženih društvenih fenomena, od kojih je najvažniji fenomen bila suvremena popularna kultura.

Uz činjenicu izostanka kvalitativne sociologije u Britaniji u vremenu najpropulzivnijih i najosjetljivijih društvenih i kulturnih gibanja i promjena, zapravo ne čudi da su na mjesto britanske sociologije došli upravo kulturalni studiji. Britanski kulturalni studiji pojavljuju se sredinom dvadesetoga stoljeća, a trajno su nastali na Sveučilištu u Birminghamu kao dio poslijediplomske nastave ${ }^{6}$. Osim što samostalno funkcioniraju kao projekt ili orijentacija izuzetnih dometa u analitičkim razmatranjima kulturne zbilje, u svojoj su povezanosti sa sociologijom postali supstancijalni dio sociološke misli. Napomenuli smo da se rad britanskih kulturalnih studija promatra kao jedna od neomarksističkih teorija kulture u vidu kritike staroga marksizma (Haralambos i Holborn, 2002.:895-898; Johnson, u: Duda, 2006.; Kalanj, 200.:42-46). Uz vodeće figure i kanonske autore britanskih kulturalnih studija - Raymonda Williamsa, Stuarta Halla i E. P. Thompsona, posebnu ulogu valja pripisati i Richardu Hoggartu koji je 1964. godine u sklopu studija engleskoga jezika i književnosti ${ }^{\top}$ osnovao Centar za suvremene kulturalne studije u Birminghamu (Center for Contemporary Cultural Studies - CCCS) okupivši studente koji su diplomirali sociologiju, englesku

6 Iako su britanski kulturalni studiji u svom pravom obliku nastali tek u okviru akademske nastave, kao poslijediplomski studij, prvotno su razvijeni izvan sveučilišta. Mjesta na kojima su kulturalni studiji prvotno razvijeni bila su štoviše marginalizirana u odnosu na središte britanskoga znanstvenog života, pa Hall piše da je zajedno s Hoggartom, Williamsom i Thompsonom "pristigao iz jedne tradicije posve marginalne za centre engleskoga akademskog života", te se njihovo bavljenje pitanjima kulturne promjene, "najprije promišljalo u prljavom vanjskom svijetu" (Hall, u: Bennett, 2005.:244).

7 Ostali birminghamski sveučilišni odsjeci, a osobito sociologija, u okvirima svojih konzervativnih i tradicionalnih znanja, zgražali su se nad osnutkom Centra za suvremene kulturalne studije, središnje institucije u četiri desetljeća dugoj povijesti kulturalnih studija (Duda, 2002.). 
književnost, povijest ili filozofiju. Da su britanski kulturalni studiji u svojoj tradiciji i začetcima bili vođeni teorijskim i metodološkim alatom preuzetim iz klasičnih socioloških paradigmi, te od socioloških klasika čije smo pristupe kulturi ranije prikazali, pokazuje njihova primarna ukorijenjenost 1950-ih i 1960-ih godina u tekstovima Webera, Marxa, Mannheima, čikaške škole i etnografskih tradicija. Centar za suvremene kulturalne studije bio je "veliko radilište" gdje su metodička načela tamo korištena rezultirala boljim i pouzdanijim analizama različitih kulturnih fenomena od onih koje su do tada poduzimane na području društvenih i humanističkih znanosti ${ }^{8}$.

Teorijsko i metodološko pojmovlje britanskih kulturalnih studija zbog toga je važno temeljitije sagledati i razumjeti iz perspektive sociologije kao znanosti?. U sociologiji se vrlo rijetko spominje najutjecajnije djelo britanskih kulturalnih studija, knjiga Richarda Hoggarta Uporabe pismenosti (The Uses of Literacy), koje se istovremeno smatra pažljivom sociološkom interpretacijom. Hoggart primjenjuje literarno-kritičku metodu "pomnoga čitanja" (close reading) na sociološko interpretiranje značenja iščitanih iz življene kulture, što rezultira vrstom metode koja je kompleksnija, potpunija i bogatija od tadašnje standardne empirijske sociološke metode ${ }^{10}$. Zato kritičari

\section{8} ovome se radu bavimo sociologijom i britanskim kulturalnim studijima kao njihovim komplementarnim i konstitutivnim dijelom, naglašavajući one dimenzije i sociologije i britanskih kulturalnih studija koje su zajedničke za oba područja. Rad o sociologiji i kulturalnim studijima na kojeg treba upozoriti, a koji polazi iz drugih teorijskih perspektiva, te je više okrenut na isticanje različitosti tih dvaju područja i govori o mogućnostima njihova dijaloga, tekst je Igora Bezinovića Prema dijalogu sociologije i kulturalnih studija (2004.).

9 S obzirom da je ovaj rad usredotočen na isticanje najsrodnijih veza britanskih kulturalnih studija i sociologije, jasno je da izostavlja iz analize neka paradigmatska djela britanskih kulturalnih studija. Zbog toga uz navedena djela britanskih kulturalnih studija u ovome radu (Richard Hoggart, Uporabe pismenosti (The Uses of Literacy), S. Hall i T. Jefferson, Otpor kroz rituale. Supkulture mladih u poslijeratnoj Britaniji (Resistance Trough Rituals. Youth Subculturesin Post-War Britain), E. P. Thompson, Stvaranje engleske radničke klase (The Making of the English Working Class), Paul Willis Učenje rada (Learning to Labour), Richard Johnson Što su uopce kulturalni studiji?(What is Cultural Studies Anyway?)) valja upozoriti na izostavljena djela koja su uz navedena bila najvažnija za konstituiranje i razvoj britanskih kulturalnih studija, odnosno Centra za suvremene kulturalne studije u Birminghamu. Riječ je o djelima Raymonda Williamsa, Kultura i društvo (Culture and Society), Duga revolucija (The Long Revolution), Granična zemlja (Border Country), Od kulture do revolucije (From Culture to Revolution), Komunikacije (Communications), zatim o djelima Stuarta Halla, Kodiranje i dekodiranje u televizijskom diskursu (Encoding and Decodingin the Television Discourse), Nadgledanje krize: Pljačka, država, zakon i red (Policing the Crisis: Mugging, the State and Law and Order) te o djelu Angele McRobbie Feminizam i kultura mladib (Feminism and Youth Culture).

10 Hoggart rekonstruira svakodnevni život engleske radničke klase pomoću vlastitih bogatih iskustava iz djetinjstva i odrastanja, što mu omogućuje iščitavanje te kulture iznutra. Zatim metodom sitničave, kritičke, mogli bismo reći, pretjerano pedantne pozornosti prema nijansama svakodnevnoga života, proučava kako se socijalno konstruiraju značenja jedne zajednice. Analiza vrijednosti jasno je utemeljena u konkretnoj i metodičkoj deskripciji običaja, normi i navika koje obilježavaju način života urbane radničke klase u industrijskoj zoni sjeveroistočne Engleske (Hoggart, 1958.). 
ističu da Hoggart u svojim istraživanjima koristi metodu sociološke hermeneutike, te da djelo nepravedno ostaje u sjeni akademske sociologije (Passeron, u: Gray et al., 2007.:31-34). Djelo Paula Willisa Learning to Labour također je sociološki klasik i klasik kulturalnih studija. Willis govori o svojevrsnom fatalizmu radničke klase izraženom u tome da djeca radnika dobivaju radničke poslove. U knjizi je izneseno tumačenje o ukotvljenosti u okvire vlastite klase (Willis, 1981.). Još jedan od vodećih kulturalista, E. P. Thompson, piše knjigu Stvaranje engleske radničke klase (The Making of the English Working Class) koja otvara srodna sociološka pitanja. Radnička klasa kao kulturalna forma zapravo je proizvod društva, odraz kontingentnih društvenih odnosa. Iako je u ranom radu britanskih kulturalnih studija riječ o sociološkoj kategoriji klase koju danas možemo uvjetno označiti "preživjelom" sociološkom kategorijom ${ }^{11}$, to nije razlog da se o kanonskim djelima britanskih kulturalnih studija, koja su, kako smo pokazali, bitno sociološke naravi, ne raspravlja u okvirima sociologije. Djelovanje i rad ostalih kulturologa i sociologa u birminghamskom Centru za suvremene kulturalne studije, primjerice Raymonda Williamsa, Johna Solomosa, Boba Findlaya, Paula Gilroya, Stuarta Halla, Richarda Johnsona, upozorenje su sociologiji da se započne ozbiljnije baviti fenomenom popularne kulture. Osim što su se ovi teoretičari britanskih kulturalnih studija u svome radu bavili kategorijama koje se već na prvi pogled mogu označiti kao sociološke, te ih već zbog toga iz sociološke perspektive valja pomnije razmotriti, još je važnije da su njihova istraživanja pružila uvid u kompleksne društvene odnose identiteta, etniciteta, rase i klase u povijesnim i diskurzivnim kontekstima, te se inzistiralo na sagledavanju društva i klasa unutar njih kao odraza kontingentnih i dugotrajnih kulturalnih i društvenih procesa. Kada Stuart Hall britansku školu kulturalnih studija definira kao "kritičku sociologiju kulture", odnosno kao "proučavanje odnosa među elementima u cjelini načina života", on time ističe da je glavni cilj analize kulture u tome da utvrdi prirodu organizacije koja tvori kompleks tih odnosa. Zato je jedan od najvažnijih socioloških aspekata kulture u kulturalnim studijima onaj da kulturalni procesi uz to što postaju autonomni, funkcioniraju i kao elementi organizacije socijalne prakse, kao njezini specifični obrasci (Hall, 1994., u: Kalanj, 2000.:42). U skladu s time je i preokupacija Raymonda Williamsa procesom kao cjelinom, što nije tek apstraktno teorijsko načelo, već tkivo njegove intelektualne prakse.

Kao što smo već i naznačili, britanskim kulturalnim studijima pristupa se iz sociološke perspektive zato što su uvelike obogatili marksističku sociološku teoriju te su anticipirali nove teorijske postavke u tadašnji ortodoksni, ekonomsko determinirani marksizam. Haralambos i Holborn u svom udžbeniku sociologije - Sociologija.

11 Niz studije provedenih u Britaniji od 1970-ih godina do danas pokazuju da velika većina stanovništva vjeruje da je društvo podijeljeno u društvene klase (Haralambos i Holborn, 2002.:284.). S druge strane, neki autori govore o kraju klasnoga društva i smrti klase. U svojoj knjizi The Death of Class (1996.) australski sociolozi Jan Pakulski i Malcolm Waters pišu da je, poput etno ogrlica i beretki a la Che Guevara, i klasa izašla iz mode, naročito među zagovornicima postmodernističke avangarde i praktičarima nove spolno-centričke, ekocentričke i etnocentričke politike. Smatraju da je sve više empirijskih dokaza da klasa gubi svoje značenje (Haralambos i Holborn, 2002.:119). 
Teme i perspektive, pišu o birminghamskom Centru za suvremene kulturalne studije unutar poglavlja o Kulturi i identitetu, pod naslovnom jedinicom neomarksističkih teorija kulture (Haralambos i Holborn, 2002.:895-898). Marksizam je, kao sociološka teorija društva, najvažnija podloga za cjelokupan razvoj britanskih kulturalnih studija i gotovo su sve njihove (mnogobrojne) forme pod znatnim utjecajem marksizma. Dean Duda piše da niti jedan diskurs u kulturalnim studijima nije prošao mimo marksizma - "svaki se s njim negdje križa, dodiruje, dijalogizira" (Duda, 2002.:48). John Fiske također navodi da su neke osnovne marksističke pretpostavke karakteristične za britanske kulturalne studije (Fiske, 1996.). Richard Johnson u svom eseju Što su uopce kulturalni studiji? (What is Cultural Studies Anyway?) iznosi tri pretpostavke kojima vrlo jasno prikazuje gdje je i kako je na britanske kulturalne studije utjecao Karl Marx. Kao prvu pretpostavku Johnson navodi da su kulturni procesi tijesno povezani s društvenim odnosima, osobito s klasnim odnosima i klasnim formacijama, s podjelama prema spolu, s rasnim strukturiranjem društvenih odnosa i s dobnom opresijom, kao oblikom ovisnosti. Druga je pretpostavka da kultura podrazumijeva moć i pomaže stvaranju nejednakosti u sposobnostima pojedinaca i društvenih skupina da odrede i ostvare svoje potrebe. Treća, koja proizlazi iz prve dvije, ističe da kultura nije ni nezavisno ni izvana određeno područje, nego poprište društvenih razlika i sukoba (Johnson, u: Duda, 2006.:65). Građenje kulturalnih studija na marksističkim pretpostavkama i marksističkoj kritici u najizravnijem i najširem smislu povezuje sociologiju i kulturalne studije. Britanski kulturalni studiji, vodeći se marksističkim pretpostavkama, izvode vrijedne analize o kulturi i moći koje postaju važan i nezaobilazan dio sociološke i kulturološke misli te ih treba pomnije sociološki obraditi.

\section{Sociopolitološka problematizacija kulture}

Temeljni teorijski i istraživački stav britanskih kulturalnih studija sadržan je u analitičkom povezivanju kulture i moći. Analitičko povezivanje kulture i moći odnosi se na smještanje kulture u kontekst socijalno-političkih odnosa te na analizu kulture kao reproduktivne dimenzije stratifikacije, diferencijacije, moći i dominacije. Upravo to daje orijentaciji britanskih kulturalnih studija posebnu aktualnost u novijoj konstelaciji socioloških ideja. Najvažniji teorijski oslonac britanskim kulturalnim studijima društveno je i kulturološki itekako dalekosežan rad talijanskoga marksista Antonija Gramscija, a iznesen je u njegovim posthumno objavljenim Bilježnicama iz zatvora $^{12}$ (Quaderni dal carcere, Prison Notebooks). Najmanje ćemo pogriješiti ako Antonija Gramscija nazovemo marksističkim filozofom, uzimajući u obzir njegovo

12 Antonio Gramsci (1891. - 1937. ) za svojega života nije objavio niti jednu knjigu. Bio je optužen i zatvoren radi komunizma 1926. godine. Na služenju dvadesetogodišnje zatvorske kazne u Turi pored Barija, 1929. godine počinje pisati svoje opservacije o talijanskom društvu i politici, i to na školskim bilježnicama. Više od pedeset bilježnica na 3000 stranica, koje su nastajale osam godina, poslije njegove smrti objavljene su pod nazivom Bilježnice iz zatvora (Quaderni dal carcere). Prvi puta su izdane u šest svezaka, između 1948. i 1951. godine, i već tada postaju vrhunsko djelo na području filozofije, politike, kulture i sociologije. Kasnije je izdano još jedno Gramscijevo djelo, njegova Pisma iz zatvora. 
zanimanje za djelo i misli prvenstveno Benedetta Crocea, te uzimajući u obzir širinu njegova znanja i djelovanja na polju kulture, politike i ideologije. Iako rođen davne 1891. godine u malom gradu na jugozapadu talijanske Sardinije, Antonio Gramsci jedna je od najvažnijih ličnosti kada je riječ o analizi kulture i praktične politike ${ }^{13}$. Njegove su ideje i danas temelj mnogih suvremenih sociokulturnih i sociopolitoloških razmatranja. Zbog toga ne treba čuditi njegov doprinos britanskim kulturalnim studijima. Johnson govori da je Gramsci snažno pojačanje već djelomično oblikovanom projektu britanskih kulturalnih studija (Johnson, u: Duda, 2006.), Stuart Hall smatra ga zaslužnim za većinu posla u konkretnoj analizi britanskih kulturalnih studija (Hall, 1980., 1996.), a Kalanj naglašava da je "otkriće Gramscija pojačalo teorijsku i konceptualnu legitimaciju britanskih kulturalnih studija” (Kalanj, 2000.:43). Gramscijev je rad tako osnova sociopolitoloških razmatranja o kulturi i moći te u skladu s tim čini najvažniji dio sociološke dimenzije britanskih kulturalnih studija. Gramsci najjasnije prikazuje kako kultura funkcionira na polju političkoga, odnosno kako se ona oblikuje i koristi kao resurs političke moći. Dato pitanje kao središnje i povlašteno društveno pitanje predstavlja presudan argument za šire sagledavanje sociopolitološkoga naslijeđa britanskih kulturalnih studija i Gramscijevoga rada na području sociologije.

Prije no što započnemo s iznošenjem glavnih sociokulturnih uvida Gramscijevoga rada i njegovoga sociološkog značaja, u kratkim ćemo crtama prikazati društvenopovijesni kontekst sedamdesetih godina dvadesetoga stoljeća u kojemu se nužno pojavljuje potreba za sociopolitološkim pristupom kulturi unutar kojega i britanski kulturalni studiji kao neomarksistička teorija kulture zauzimaju svoje mjesto. Sociopolitološka problematizacija kulture oblikovana je početkom 1970-ih godina u specifičnom stjecaju okolnosti toga razdoblja gdje su liberalni, socijalno-državni i socijalistički projekti, kao tri dominantna projekta ekonomsko-političke racionalnosti, doživjeli radikalne preinake. Uz te osjetne političke preinake, središnju ulogu odigrala je i teorijska i ideološka "dekonjunkturizacija" marksizma. "Socijalni i kulturno-ideologijski projekt marksizma tih je godina iscrpio svoju mobilizacijsku i modernizacijsku snagu" (Kalanj, 2000.:38). Time je poljuljan jedan tip izvjesnosti sociološkog mišljenja o kulturnoj sferi i pretpostavljenom poretku ideja. Velike političke i društvene promjene s početka 1970-ih godina, koje je Derrida ocrtao kao "preokret u hijerarhiji diskursa" te "raskol i decentriranje do tada neprikosnovenih subjekata povijesti” (Derrida, u: Culler, 1991.:73-75), odrednice su sociopovijesnoga i sociopolitološkoga okvira unutar kojeg se pojavljuju britanski kulturalni studiji.

U novim socijalnim okvirima u kojima marksizam kao vodeći društveni, kulturni i ideološki projekt više nije mogao opstati, redistribucija političke moći i utjecaja pojavljuje se kao bitno pitanje. "Socijalna se mobilizacija subjektivira u raznovrsnosti političkih oblika, a političke se inicijative legitimiraju kao kulturni pokreti usredotočeni na zauzimanje civilnoga društva kao prostora autonomije i emancipacije" (Kalanj, 2000.:39). Otuda je jasno zbog čega gotovi svi društveni pokreti s početka 1970-

$\mathbf{1 3}$ Iako za kontekst ovoga rada to ne igra veliku ulogu, treba naglasiti da je Gramsci bio jedan od utemeljitelja i vođa Komunističke partije Italije. 
ih godina (feministički, ekološki, mirovni, ...), prije svega naglašavaju svoj kulturni smisao. Za izlazak neke zemlje iz nerazvijenosti od 1970-ih godina nadalje više nisu dovoljne samo mjere za poticanje ekonomskoga rasta, već jednako važni (i važniji) postaju faktori kulture koji odlučuju kako će se neko društvo politički organizirati za razvoj. U sociokulturološkom pojmovlju događaju se supstancijalne preobrazbe koje izravno utječu na likove kulture pa tradicionalni socioantropološki pristup kulturi, ponajviše utemeljen na izvrsnim radovima C. Levija-Straussa i njemu bliskih socijalnih mislilaca ${ }^{14}$, postaje nedovoljan za sagledavanje suvremenih kultur(al)nih zbivanja. Iako čvrsta opstojnost tradicionalnoga socioantropološkog pristupa kulturi ne može biti dovedena u pitanje, taj pristup, koji se ustrajno zadržava na definiciji kulture određene implicitnim obilježjima, vrijednostima, normama, vjerovanjima i stavovima, u suvremenim društvima postaje itekako nedostatnim. Sociokulturni okviri u kojima su politički procesi zadobili ključnu ulogu u rekonstelaciji ekonomskih i socijalnih odnosa zahtijevali su oblikovanje sociopolitološkoga pristupa kulturi. Osim obilježenosti toga pristupa političkoj moći, taj je pristup nužno obilježen i načinima, odnosno posrednicima širenja te moći. Dakle, osim što sociopolitološki pristup kulturi, unutar kojega svrstavamo i britanske kulturalne studije, pokazuje da je kultura neodvojiva od pojma moći, usporedno s time pokazuje i da je neodvojiva od komunikacijske sfere te da dolazi do eksplozivnoga i nagloga razvoja novih kulturnih proizvoda i konstrukcija koji u epohi globalizacije postaju glavne kulturne ekspresije.

Današnja je kultura gotovo u cijelosti eksplicitna, ona je izražena putem tiska, televizije, interneta i ostalih elektronskih medija. Svi ti posrednici oblikuju popularnu kulturu te čine njenu osnovu u modernom svijetu (During, 2005.). Današnja je kultura utemeljena na informacijama, zabavi, znanosti i tehnologiji, te je tek analizom sadržaja tih eksplicitnih društveno-kulturnih oblika moguće shvatiti ulogu kulture u modernom svijetu. Susman još krajem 1980-ih godina govori da je djelovanje po kojem se kultura zbiljski događa komunikacija i da su kultura i komunikacija danas dva nerazdvojna pojma (Susman, 1987.). Vodeći se mislima o komunikaciji kao univerzalnom obrascu i okviru današnjega kulturnog procesa, Kalanj 2000. godine zapisuje da je uklopljenost kulturno-komunikacijskoga sklopa u mrežu ekonomske i političke moći teorijski posve evidentna činjenica. Na toj je činjenici utemeljen sljedeći slogan: "Vladavina nad komunikacijskim poljem manifestno se odvija kao 'prirodno-kulturni' proces, kao opći objektivitet koji ne pravi nikakve razlike ni diskriminacije, ali iza tog video-kulturnoga objektiviteta stoje interesni mehanizmi ekonomskoga utjecaja i regulative političke moći" (Kalanj, 2000.:41). Ne možemo ne primijetiti sličnost slogana sa zapisom istaknutoga grčkog filozofa, sociologa, ekonomista i psihoanalitičara Corneliusa Castoriadisa: "Na planu zbiljskoga funkcioniranja društva moć naroda samo je paravan za moć novca (...) Kaže se: Svaki je pojedinac

${ }^{14}$ Rade Kalanj u svojoj knjizi Ideje i djelovanje između ostalog piše o suvremenim sociološkim kretanjima u kulturi polazeći od triju temeljnih orijentacija: sociologističke, socioantropološke i sociopolitološke orijentacije. Kalanj izlučuje svoj teorijski okvir iz tipologije novih pristupa kulturi Neila Smelsera čiji rad, uz rad Diane Crane, smatra metodički najkoherentnijim u analitičkom bavljenju suvremenim kulturnim procesima (Kalanj, 2000.). 
slobodan, a ustvari svi pasivno prihvaćaju jedini smisao što ga predlažu i doista nameću društvene institucije" (Castoriadis, 1994.:48).

Iako je danas zapadni svijet još snažnije i naglašenije određen diktatom medija i tehnologije (u toj mjeri da oni postaju gotovo samosvrhovitima), i u kojemu globalizacija i neoliberalni kapitalizam neprestano probijaju svoje granice, još uvijek možemo braniti navedene slogane. S obzirom da su suvremeni sociokulturni procesi i dalje svojim najvećim dijelom obilježeni distribucijom kulturne moći, u sociološkoj analizi suvremene kulture nužno je krenuti od Antonija Gramscija, kanonskoga autora britanskih kulturalnih studija, koji ta kretanja naznačuje već krajem dvadesetih i početkom tridesetih godina dvadesetoga stoljeća. Sa sociološkoga stajališta, Gramscijevi uvidi uvažavaju tradicionalno socioantropološko poimanje kulture kao implicitnoga skupa vrijednosti, normi, vjerovanja i stavova, te najavljuju sociopolitološko poimanje kulture, odnosno oblikovanje razgranatoga kulturno-komunikacijskog sklopa koji postaje sve važniji za prakticiranje moći u demokratskom društvu (Kalanj, 2000.:42). Gramscijevo pojmovlje, a osobito njegov pojam kulturne hegemonije, najjasnije pokazuje da je u kulturi sadržan realitet političke moći. Tamo gdje se "vladavina nad kulturno-komunikacijskim poljem odvija kao prirodno-kulturni proces" pojavljuje se Gramscijev osnovni pojam kulturne hegemonije. Kulturna hegemonija jest osvajanje političke moći, ali na nov način - sredstvima kulture. Na terenu civilnoga društva, koji je, također, jedan od osnovnih Gramscijevih pojmova, gdje postoje razvijene državne institucije, osvajanje aparata kulture najefikasnije je demokratsko sredstvo za postizanje političke prevlasti. Kulturna hegemonija tako je širenje i ozbiljenje ideologije, svjetonazorskih ideja, u širokoj skali ustavnoga civilnog društva (Bobbio, 1969., u: Kalanj, 2000.:41). Gramsciju je svakako bilo stalo do osvajanja političke vlasti, ali mu je istodobno bilo jasno da tu vlast treba osvojiti posredstvom kulture, odnosno da ju treba realizirati preko razgranate kulturne sfere u kojoj se reproduciraju i legitimiraju odnosi moći. Buržoaska vladajuća klasa da bi postigla pristanak naroda da nad njime vlada, posvećuje svu svoju energiju i resurse aktualnoj zadaći organiziranja njihova pristanka. Buržoaska vladajuća klasa to postiže šireći svoju kulturu i ideologiju u sve institucije i strukture modernoga civilnog društva ${ }^{15}$. Umjesto prisile, kulturna hegemonija odnos je dominacije koji prihvaćaju oni kojima se dominira (Hall, Lumley, McLennan, 2007.:278-305). Weberovskim rječnikom, moć buržoazije nad narodom postaje posve legitimnom vlašću jer taj narod pristaje na to da se njime vlada. Svi glavni ideološki aparati države i građanskoga društva posvećeni su zadobivanju djelatne potpore naroda - od školovanja preko javnih medija do institucija umjetnosti i kulture (Gramsci, 1971.:240-258). Krovni pojam koji okuplja sva Gramscijeva sredstva u ostvarenju hegemonije je kultura kao sveprisutni element ideologije, države, građanskoga društva i gospodarstva. Bennett, imajući to na umu, piše da Gramsci provodi kulturaciju socijalnih odnosa (Bennett, 2005.:244). Stoga je kulturna hegemonija ideološka i kulturna konstrukcija koja, uz uposlenost svih ideoloških aparata države, pruža narodu dojam da je njihov prista-

15 Na Gramscijevu se teoriju kasnije oslanja i Louis Althusser koji definira ideološke aparate države kao "određen broj činjenica koje se neposrednom promatraču prikazuju u obliku raznolikih i specijaliziranih institucija" (Althusser, 1986.). 
nak na to da se nad njime vlada, posve prirodan i normalan. Navedena kulturna hegemonija zapravo je dio "video-kulturnoga objektiviteta iza kojega stoje interesni mehanizmi ekonomskoga utjecaja i regulative političke moći”. Gramscijeva vladajuća klasa svoj svjetonazor i interes nastoji poopćiti na štetu ostalih društvenih slojeva. "Podređene grupe prihvaćaju taj svjetonazor kao zajedničku stvar, ali prihvaćajući vjerovanja i vrijednosti koje opravdavaju nejednaku razdiobu društvene moći i probitačnosti, one u stvari pridonose vlastitoj podložnosti" (Kalanj, 2000.:102). Osim što je nejednakost neizbježna zbog postojanja vladajuće političke klase, buržoazije, koja svoju moć širi na štetu drugih klasa u društvu, ta je nejednakost ujedno ugrađena u društvene institucije i kulturnu sferu. Statusno-konvencionalno društvo s obrascima nejednakosti koji su ukorijenjeni u kulturnoj sferi podrazumijeva distribuciju kulturne moći, odnosno reproduciranje odnosa moći u kulturi, što danas rezultira još jednom vrlo važnom ambivalentnošću suvremene kulture.

Ambivalentnost je izražena u porastu moći i istovremenom porastu odnosa bezličnosti u društvu. Tu ambivalentnost izvrsno opisuje Jean Baudrillard u svojim dalekosežnim sociološkim razmatranjima u kojima svijet medijske kulture promatra kao svijet simulakruma dovodeći distribuciju moći u kulturno-komunikacijskom sklopu do krajnjih konzekvencija. Baudrillard je razvoj tehničkih medija i medijatizaciju kulture označio kao ključne procese modernoga društva. Upozorio je da svijet medijske kulture s podrškom eksplozivnoga razvoja tehnologije postaje poruka snažnije nego ikad prije. Razvoj tehničkih medija i medijatizacija kulture srž su (post) modernoga vremena u kojem živimo i kojega zbog toga nazivamo i društvom rizika (Beck, 1992.) i društvom spektakla (Debord, 1967.). Govoreći da se veliki humanistički kriteriji vrednovanja i vrijednosti civilizacije tope u sistemu slika i znakova (Baudrillard, 1983.), Baudrillard dovodi do krajnjih granica sociopolitološki teorijski pristup kulturi. Kulturna je moć za Baudrillarda, zahvaljujući tehničkoj medijatizaciji i uvećanoj tehnološkoj reproduktivnosti, utjelovljena u sferi slike. Posljedica takvoga eksplozivnog razvoja suvremene kulture je sve više informacija, a sve manje mišljenja. Informacijski mediji kao temeljni posrednici suvremene kulture, izvanjski prividno proizvode sve više društvenosti, a iznutra neutraliziraju socijalne odnose i društvenost samu. Baudrillard govori da je na djelu leukemizacija socijalne supstancije (Baudrillard, 1981.:231), što se odvija istodobno s implozijom smisla i implozijom socijalnoga u masi (Smart, 1992.:175). Unatoč postmodernističkim temeljima i apstraktnosti Baudrillardove teorije o simulaciji i simulakrumu koja je iz sociološke perspektive velikim dijelom nepotkrijepljena, pojedini dijelovi te teorije upozoravaju na neke od očiglednih posljedica distribucije kulturne moći te u suvremenom društvu pronalaze svoju potvrdu. Slijedom primjera i raznih polazišta za sociokulturnu analizu, dolazimo do toga da se razumijevanje strukturalnoga međuodnosa društva i kulture krije u razumijevanju mehanizma kulturne moći u suvremenom društvu. Distribucija kulturne moći temeljni je stav i Michaela Foucaulta, jednoga od najvećih socijalnih mislilaca dvadesetoga stoljeća. Njegov stav je izražen u misli da je cijela moderna kultura zapravo golemi mehanizam moći (Foucault, 1994.).

Zbog aktualnosti sociopolitološkoga pristupa kulturi, kojega su britanski kulturalni studiji zagovarali, te čiji je osobito Gramscijev rad neizostavan dio, nužno je šire uvr- 
štavanje Gramscijevih sociopolitoloških kategorija i procesa na područje sociologije i sociologije kulture.

\section{Kulturalni studiji kao dio akademske sociologije u Hrvatskoj}

U Hrvatskoj su kulturalni studiji relativno nova akademska praksa. Prvi puta pojavili su se 2002. godine na Filozofskom fakultetu u Zagrebu kao dio poslijediplomske nastave pri Odsjeku za komparativnu književnost. 2004. godine osnovan je zaseban Odsjek za kulturalne studije na Filozofskom fakultetu u Rijeci, gdje se sagledavaju u punini svojih multidiskurzivnih značenja, kao disciplina koja predstavlja "motor interdisciplinarnosti i kritičkoga duha akademije" (Sveučilište u Rijeci, Filozofski fakultet, Odsjek za kulturalne studije, 2011.). U Osijeku se predavanja o kulturalnim studijima izvode kao dio Odjela za kulturologiju (Sveučilište u Osijeku, Odjel za kulturologiju, 2011.). U Zagrebu, unatoč tome što je hrvatska akademska metropola, kulturalni studiji ne postoje kao zaseban odsjek. U sklopu akademske nastave na hrvatskim odsjecima za sociologiju u sklopu Filozofskih fakulteta, bavljenje kulturalnim studijima novijega je datuma i oni su kao zaseban kolegij dio ukupne nastave na Odsjeku za sociologiju Filozofskoga fakulteta u Splitu (kao izborni kolegij) te u Zadru (kao obvezatni kolegij). Na zagrebačkom Filozofskom fakultetu na Odsjeku za sociologiju kulturalni studiji nisu dio obvezatne niti dio izborne nastave. Izvodili su se vrlo rijetko i kao dio poslijediplomske nastave. Činjenica uvođenja kolegija o kulturalnim studijima na odsjecima za sociologiju Filozofskih fakulteta u Zadru i Splitu, te neuvođenja kulturalnih studija kao kolegija na Odsjek za sociologiju Filozofskoga fakulteta u Zagrebu, može upućivati na svojevrsnu zatvorenost zagrebačkoga akademizma. Iako su oblici sveučilišne zatvorenosti tema čija eksplikacija zahtijeva posebnu obradu i prije svega istraživanje, ipak možemo konstatirati da je nepostojanje kolegija o kulturalnim studijima na sociološkom odsjeku Filozofskoga fakulteta u Zagrebu, koji je dio najrazvijenijeg hrvatskoga Sveučilišta, nedostatak toga odsjeka.

Stoga treba postaviti pitanje i istražiti upućuje li prisutnost kolegija o kulturalnim studijima na odsjecima za sociologiju Filozofskih fakulteta Sveučilišta u Zadru i Splitu, te istodobna neprisutnost toga kolegija na Odsjeku za sociologiju Filozofskoga fakulteta Sveučilišta u Zagrebu, na bolju razvijenost i veću akademsku otvorenost pojedinih sociologija, u ovom slučaju sociologije kulture, na tim, u ovom trenutku svakako manje razvijenim sveučilištima?

Ako postavimo drugo pitanje, na koji je način obrađen sadržaj kulturalnih studija na postojećim kolegijima o kulturalnim studijima u sklopu socioloških odsjeka, mogli bismo reći sljedeće. Na temelju uvida u izvedbene programe socioloških kolegija o kulturalnim studijima na vodećim hrvatskim sveučilištima u Zagrebu, Splitu i Zadru, te izuzimajući riječko i osječko sveučilište koji imaju zasebne odsjeke za kulturalne studije (Odsjek za kulturalne studije u Rijeci izvodi se u sklopu Filozofskoga fakulteta, Odjel za kulturologiju dio je Sveučilišta u Osijeku), možemo konstatirati da sociolozi u Hrvatskoj u bavljenju kulturalnim studijima ili ne ističu ili ističu tek manji broj teorijskih i istraživačkih uvida kulturalnih studija. 
Kurikulum kolegija Kulturni studiji, koji se izvodi kao obvezatni kolegij u sklopu Odsjeka za sociologiju u Zadru, sadržajno je zaokupljen društvenim položajem i kulturom mladih u poslijeratnoj Britaniji (Izvedbeni program kolegija Kulturni studiji, 2011.). Fenomen poslijeratnih supkultura mladih u Britaniji, iako vrlo bitan sociološki fenomen za kojega kulturalni studiji nude razne nove uvide i istraživačke pristupe, zasigurno nije jedini sociološki fenomen kojega kulturalni studiji mogu upotpuniti i proširiti. Britanski kulturalni studiji na svom su razvojnom putu (mijenjajući u svom vremenskom razvoju naglasak s jedne na drugu sociološku kategoriju) primarno bili zaokupljeni popularnom kulturom, kulturom radničke klase, supkulturnim stilovima, pitanjima nacionalnoga identiteta, pitanjima kolonijalizama i postkolonijalizama, rasom i etničnošću, rodom i spolnošću, politikom identiteta, medijima, potrošnjom, ideologijom, postmodernom kulturom, globalizacijom, ekonomijom, kulturnom politikom, obrazovanjem. Sve te sociološke kategorije kojima su se bavili kulturalni studiji mogu biti sagledane, te po potrebi preispitane u okviru sociologije. Naposljetku, i supkulture mladih, kao jedan od središnjih socioloških pojmova koje kulturalni studiji svojim analizama upotpunjuju i obogaćuju, određeni su svojim položajem unutar odnosa moći te su odraz kontingentnih i složenih odnosa kulture i moći. Na sveučilišnim odsjecima za sociologiju kolegiji koji obrađuju fenomen poslijeratnih supkultura iz perspektive britanskih kulturalnih studija, trebali bi se pored životnih stilova supkultura te njihovih vizualnih i semantičkih obilježja vidljivih u načinu odijevanja ili slušanju određene glazbe, baviti Gramscijevim konceptom kulturne hegemonije i drugim konceptima kulturne moći koji su jednako kao i životni stil vitalna obilježja tih supkultura. U uvodnom tekstu zbornika Otpor kroz rituale (Resistance Trough Rituals) (1976.), naslova Subcultures, Cultures and Class: A Theoretical Overview, John Clarke, Stuart Hall, Tony Jefferson i Brian Roberts, vođeni Gramscijevim idejama, izložili su teorijski pristup za istraživanje supkultura mladih. Clarke i ostali pripadnici birminghamske škole polaze od pretpostavke da će kultura dominantnih grupa uvijek biti moćnija od supkultura kao kultura grupa s manjom moći. Kulturne konfiguracije koje supostoje s vladajućom klasom neće biti tek podređene tom dominantnom poretku, već će ulaziti s njim u borbu, nastojat će ga mijenjati, odupirat će mu se ili čak svrgnuti njegovu vladavinu - njegovu hegemoniju. Tako borba između klasa oko materijalnoga i društvenoga života ostaje uvijek stalnom borbom oko raspodjele kulturne moći (Clarke et al., u: Hall i Jefferson, 1976.:11-19).

Sadržaj kolegija Kulturalne studije koji se izvodi u sklopu Odsjeka za sociologiju na Filozofskom fakultetu u Splitu obuhvaća puno širu literaturu i s time u skladu više fenomena, analiza, stavova i metodologije koje kulturalni studiji nude sociologiji (3.2.2. Opis izbornih predmeta Nastavnoga programa jednopredmetnog studija sociologije u Splitu, 2011.).

\section{Zaključak}

Sažetim kronološkim prikazom koncepta kulture u sociologiji pokazali smo da su se uloga i status kulture mijenjali kroz njenu povijest, bivajući više istaknutima ili više zanemarenima u skladu sa zahtjevima same sociologije u sinkroniji njezina razvoja. 
Istaknuli smo da je sociologija u vremenu svoje institucionalizacije bila privržena uzoru stroge racionalnosti te da su nastanak sociologije kao posebne znanosti, njezina disciplinarna diferencijacija i specijalizacija, te metodološka i konceptualna izgradnja, bili posredovani momentom stroge znanstvenosti. Britanske smo kulturalne studije u raspravu uveli kao svojevrsni izazov disciplinarnom identitetu sociologije. Zbog toga što je sociologija u Britaniji sredinom dvadesetoga stoljeća iz svojih glavnih tokova isključivala istraživanja o kulturi, na njeno su mjesto došli upravo britanski kulturalni studiji. Britanski kulturalni studiji oduvijek su bili izuzetno povezani sa sociologijom, a do sada nije, osobito u sociologiji, dovoljno problematizirana niti na pregledan način iznesena njihova sociološka dimenzija. Britanski kulturalni studiji nude niz društvenih analiza i pristupa kojima obogaćuju i osvjetljavaju sociološki pristup te djeluju kao jedna vrsta eklektične sociologije u godinama kada sociologija sama nije bila u mogućnosti pružiti kvalitetan (kao i kvalitativan) alat za analizu tada sveprisutnih, a neistraženih društvenih fenomena, od kojih je najvažniji fenomen bila suvremena popularna kultura. Upozorili smo na nužno preispitivanje niza djela i pojmovlja britanskih kulturalnih studija iz sociološke perspektive. Knjiga Richarda Hoggarta Uporabe pismenosti (The Uses of Literacy) smatra se pažljivom sociološkom interpretacijom, a u akademskoj sociologiji uopće se ne spominje. Djelo Paula Willisa Learning to Labour također je sociološki klasik koliko i klasik kulturalnih studija, a ni o njemu se na području sociologije ne raspravlja. Najvažnija poveznica sociologije i britanskih kulturalnih studija je marksizam. Kao neomarksistička teorija kultura britanski su kulturalni studiji uvelike obogatili marksističku sociološku teoriju te su anticipirali nove teorijske postavke u tadašnji ortodoksni, ekonomsko determinirani marksizam. Najsnažniji teorijski oslonac te konceptualna legitimacija čitavom projektu britanskih kulturalnih studija je rad Antonija Gramscija predvođen njegovim konceptom kulturne hegemonije koji najjasnije ocrtava sociopolitološki pristup kulturi te prikazuje kako kultura funkcionira na polju političkoga, odnosno kako se ona oblikuje i koristi kao resurs političke moći. Naznačili smo da su prisustvo realiteta političke moći u kulturi i izražavanje kulture u obliku eksplicitnih komunikacijskih formi koje su danas dovedene do svojih krajnjih granica, središnje i povlašteno pitanje suvremenoga društva, te zbog toga Gramscijeve ideje koje naznačuju ta suvremena sociokultur(al)na pitanja zaslužuju pomniji sociološki pristup.

Još jednom treba istaknuti da britanski kulturalni studiji sadrže vrijedne teorijske i pouzdane metodološke uvide o brojnim društvenim fenomenima među kojima su: popularna kultura, kultura radničke klase, supkultura, identitet, (post)kolonijalizam, rasa, etnicitet, rod, spol, mediji, potrošnja, ideologija, postmoderna kultura, globalizacija, itd. Već s obzirom na klasifikaciju tih fenomena kao socioloških, sociologija bi se trebala više i dublje baviti radom britanskih kulturalnih studija te iz perspektive svoje znanosti preispitati navedeno pojmovlje koje nude britanski kulturalni studiji. Britanski kulturalni studiji, uz to što su nesumnjivo jedna od najutjecajnijih struja koja potiče na preispitivanje i obnavljanje teorijskih i metodoloških dosega sociologije kao znanosti, oni su i neka vrsta sociološkoga blaga, a još nisu zadobili zasluženu pažnju na području sociologije. Zbog toga je jedan od najvažnijih zahtjeva ovoga rada onaj koji poziva hrvatsku akademsku sociologiju da pomnije i temeljitije preispita rad britanskih kulturalnih studija u sociološkom kontekstu. Potrebno je, na području hrvatske akademske sociologije, ukazati na pregršt socioloških kategorija i 
značajki koje sociologiji nude britanski kulturalni studiji, odnosno potrebno je ukazati na sociološku dimenziju britanskih kulturalnih studija.

\section{Popis literature}

1. Althusser, L. (1986). Ideologija i ideološki aparati države, u: Flere, S. (Ur.). Proturječja suvremenog obrazovanja. Zagreb: RZRKSSOH.

2. Barker, C. (2003). Cultural Studies: Theory and Practice. London: Thousand Oaks. New Delhi: Sage.

3. Baudrillard, J. (1983). Simulations. New York: Semiotext(e) and Jean Baudrillard.

4. Beck, U. (1992). Risk Society: Towards a New Modernity. New Delhi: Sage.

5. Bennett, T. (2005). Kultura - znanost reformatora. Zagreb: Golden Marketing.

6. Bezinović, I. (2004). Prema dijalogu sociologije i kulturalnih studija. Diskrepancija, 5 (9).

7. Bhabha, H. (1994). The Location of Culture. London and New York: Routledge.

8. Castoriadis, C. (1994). Enmal de culture. Esprit, 205: 40-50.

9. Clarke, J.; Hall, S.; Jefferson, T.; Roberts, B. (1976). Subcultures, Cultures and Class: A theoretical overview, u: Hall, Stuart i Jefferson, Tony (Eds.). Resistance Trough Rituals. University of Birmingham: The Centre for Contemporary Cultural Studies. This edition published in Taylor \& Francis e-Library.

10. Culler, J. (2001). Kulturalni studiji i književnost, u: Književna teorija - vrlo kratak uvod. Zagreb: AGM.

11. Culler, J. (1991). O dekonstrukciji. Zagreb: Globus.

12. Nastavni plan i program sociologije. Odsjek za sociologiju u Splitu. 3.2.2. Opis izbornih predmeta. Pregledano 15.10.2011. (http://www.ffst.hr/odsjeci/sociologija/program d.pdf).

13. Duda, D. (2002). Kulturalni studiji: ishodišta i problemi. Zagreb: AGM.

14. Duda, D. (2006). Politika teorije. Zbornik rasprava iz kulturalnih studija. Zagreb: Disput.

15. During, S. (2005). Cultural studies: a critical introduction. London and New York: Routledge.

16. Durkheim, E. (2008). Elementarni oblici religijskog života. Totemistički sustav u Australiji. Zagreb: Jesenski i Turk.

17. Filozofski fakultet u Rijeci. Odsjek za kulturalne studije. Pregledano 20.9.2011. (http://www.ffri.uniri.hr/index.php?option=com depts\&Itemid=84\&task=displa y\&id=8).

18. Foucault, M. (1994). Znanje i moć. Zagreb: Nakladni Zavod Globus.

19. Gramsci, A. (1971). Selections from the Prison Notebooks. New York: International Publisher.

20. Hall, S. (1980). Cultural studies and the Centre: some problematic sand problems, in: Hall, S.; Hobson, D.; Lowe, A.; Willis, P. (Eds.). Culture, Media, Language. Working Papers in Cultural Studies 1972.-79. London: Hutchinson i CCCS.

21. Hall, S. (1996). Gramsci's Relevance for the Study of Race and Ethnicity, in: Morley, D. and Chen, K. (Eds.). Critical dialogues in cultural studies. StuartHall. London: Routledge. 
22. Hall, S. (1997). The spectacle of the other, in: Hall, S. (Ed.). Representations. London and Thousand Oaks: Sage.

23. Hall, S. (1997). Representation: cultural representations and signifying practices. London: Sage.

24. Hall, S.; Lumley, R. and McLennan, G. (2007). Politics and Ideology: Gramsci, in: Gray, A.; Campbell, J.; Erickson, M.; Hanson, S.; Wood, H. (Eds.). CCCS Selected Working Papers Volume 1. London and New York: Routledge Taylor and Francis e-Library.

25. Haralambos, M. i Holborn, M. (2002). Sociologija. Teme i perspektive. Zagreb: Golden marketing.

26. Hoggart, R. (1958). The Uses of Literacy. Harmondsworth: Penguin.

27. Izvedbeni program kolegija Kulturni studiji. Odsjek za sociologiju u Zadru. Pregledano 15.10.2011. (www.unizd.hr/sociologija).

28. Johnson, R. (2006). Što su uopće kulturalni studiji, u: Duda, D. (Ur.). Politika teorije zbornik rasprava iz kulturalnih studija. Zagreb: Disput.

29. Eagleton, T. (2002) Ideja kulture. Zagreb: Jesenski i Turk.

30. Kalanj, R. (2000). Ideje i djelovanje. Ogledi o kulturnim promjenama i razvoju. Zagreb: SE Razvoj i okoliš.

31. Long, E. (1997). From Sociology to Cultural Studies. New Perspectives. UK: Blackwell Publishers Ltd.

32. Marx, K. (1970). The German Ideology. London: Lawrence andWishart.

33. Odjel za kulturologiju Sveučilišta u Osijeku. Pregledano 15.10.2011. (http://kulturologija.unios.hr).

34. Passeron, J. C. (2007). Introduction to the French edition of Uses of Literacy, in: Gray, A.; Campbell, J.; Erickson, M.; Hanson, S.; Wood, H. (Eds.). CCCS Selected working papers Volume 2. London and New York: Routledge Taylor and Francis e-Library.

35. Polanyi, K. (1957). The great transformation. New York: Rinehart.

36. Schudson, M. (1997). Cultural Studies and the Social Construction of 'Social Construction': Notes on 'Teddy Bear Patriarchy.", in: Long, E. (Ed.). From Sociology to Cultural Studies. Oxford: Blackwell Publishers Ltd.

37. Seidman, S. (1997). Relativizing Sociology: The Challenge of Cultural Studies, in: Long, E. (Ed.). From Sociology to Cultural Studies. Oxford: Blackwell Publishers Ltd.

38. Smart, B. (1992). Modern Conditions, Postmodern Controversies. London. New York: Routledge.

39. Smelser, N. L. (1995). Sociological Theories. International Journal of Social Sciences, 139.

40. Susman, I. W. (1987). Kultura kao historija: preobražaj američkog društva u XX. veku. Beograd: Rad.

41. Tomić-Koludrović, I. (2009). Pogled u budućnost: sociologija kao multiparadigmatska, refleksivna i javna znanost. Revija za sociologiju, 40 (39) (3-4): 139181.

42. Waters, M. (1997). Inequality after class, in: Owen, D. (Ed.). Sociology after Postmodernism. Thousand Oaks: Sage.

43. Weber, M. (1968). Protestantska etika i dub kapitalizma. Sarajevo. 
44. Williams, R. (1965). The Long Revolution. Harmondsworth: Penguin.

45. Williams, R. (1983). Keywords. A vocabulary of culture and society. New York: Oxford University Press.

46. Willis, P. (1981). Learning to Labor: How Working Class Kids Get Working Class Jobs. New York: Columbia University Press.

47. Wolff, J. (1999). Cultural Studies and the Sociology of Culture. Invisible Culture: Electronic Journal for Visual Studies. Pregledano 1.10.2011. (http://www.rochester.edu/in visible culture/issue1/wolff/wolff.html). 
Pregledni rad

\title{
Andriana Benčić
}

Faculty of Humanities and Social Sciences, Post-graduate doctoral study in sociology, Croatia

e-mail: andriana.bencic@gmail.com

\section{Sociological Dimension of British Cultural Studies}

\begin{abstract}
This paper seeks to provide an extended critical overview of the sociological dimension and sociological features of British cultural studies. In this context, it offers some necessary theoretical stimulation and perspective to re-think and to re-evaluate the role of British cultural studies in the field of sociology. The multidisciplinarity of British cultural studies has always had a strong relationship with sociology. British cultural studies are in their essence some kind of eclectic sociology. The richness and quality of their own approach are an important contribution which enhances and highlights the sociological approach. Although in sociology British cultural studies are seen as one of the neo-marxist approaches to culture, the sociological dimension of British cultural studies is still not elaborated in a methodical and comprehensive way. In this work it is presented most extensively via the British Birmingham School of Cultural studies with the focus on the ideas of Antonio Gramsci which lend the strongest theoretical support to British cultural studies. Within the common sociopolitical/ theoretical framework both disciplines sociology of culture and cultural studies discuss the integration of cultural communication into a complex network of economic and political power.
\end{abstract}

Keywords: British cultural studies, sociology, culture, sociology of culture, power, sociopolitical observations of culture. 